\title{
The Time of Prenatal Androgen Exposure Affects Development of Polycystic Ovary Syndrome-Like Phenotype in Adulthood in Female Rats
}

\author{
Fahimeh Ramezani Tehrani ${ }^{1,}$; Mahsa Noroozzadeh ${ }^{1}$; Saleh Zahediasl ${ }^{2}$; Abbas Piryaei ${ }^{3}$; \\ Somayeh Hashemi ${ }^{1}$; Fereidoun Azizi ${ }^{4}$ \\ ${ }_{1}$ Reproductive Endocrinology Research Center, Research Institute for Endocrine Sciences, Shahid Beheshti University of Medical Sciences, Tehran, IR Iran \\ ${ }^{2}$ Endocrine Physiology Research Center, Research Institute for Endocrine Sciences, Shahid Beheshti University of Medical Sciences, Tehran, IR Iran \\ ${ }^{3}$ Department of Biology and Anatomical Sciences, Faculty of Medicine, Shahid Beheshti University of Medical Sciences, Tehran, IR Iran \\ 4 Endocrine Research Center, Research Institute for Endocrine Sciences, Shahid Beheshti University of Medical Sciences, Tehran, IR Iran \\ ${ }^{*}$ Corresponding author: Fahimeh Ramezani Tehrani, Reproductive Endocrinology Research Center, Research Institute for Endocrine Sciences, Shahid Beheshti University of Medical \\ Sciences, Tehran, IR Iran. P.O. Box: 1985717413, Tel: +98-2122432500, Fax: +98-2122416264, E-mail: ramezani@endocrine.ac.ir
}

Received: December 8, 2013; Revised: January 29, 2014; Accepted: February 25, 2014

Background: Polycystic ovary syndrome (PCOS) is one of the most common reproductive disorders in women. Previous studies have shown that prenatal exposure of female fetuses to androgen can be considered an important factor in the development of PCOS.

Objectives: In the present study we aimed to examine the effects of prenatal exposure of female rat fetuses to previously documented doses of testosterone on different embryonic days on the development of PCOS phenotype in adulthood.

Materials and Methods: Pregnant rats were divided into four groups, experimental and control groups. Three mg of free testosterone was administered subcutaneously to experimental group 1 on gestational days $16-19$, daily and $20 \mathrm{mg}$ on day 20 , to experimental group 2 , and the controls received solvent at the same times. Female offspring of these mothers aged between 90-100 days were examined for development and function of the reproductive system. Independent-sample student $t$ test was used to compare the results between the experimental groups and controls.

Results: Anogenital distance $(\mathrm{P}<0.001)$ and clitoris length were significantly increased in the offspring of both experimental groups $(\mathrm{P}$ $<0.001$ and $\mathrm{P}<0.05$ respectively). Nipples were not formed in the offspring of experimental group 1 , whereas in experimental group 2 the number of nipples was unchanged. Vaginal length was significantly decreased in the offspring of experimental group 1 ( $(\mathrm{P}<0.001)$, whereas in experimental group 2, no significant difference was observed. In the offspring of experimental group 1, hormonal profiles did not differ, but in experimental group 2, levels of testosterone $(\mathrm{P}<0.05)$ and $\mathrm{LH}(\mathrm{P}<0.01)$ were significantly increased, but estrogen $(\mathrm{P}<0.05)$ and anti-Mullerian hormone levels $(\mathrm{P}<0.001)$ were significantly decreased. A significant increase in the number of preantral and antral follicles was observed in the ovaries of offspring of experimental group $1(\mathrm{P}<0.05)$; whereas there was no such a difference in experimental group 2 .

Conclusions: The time of prenatal exposure to androgens may have a significant role in the development of PCOS. Increased prenatal androgen levels are associated with hormonal changes and morphological disorders of the reproductive system. Therefore, avoiding exposure to androgen excess during critical periods of fetal development may prevent or reduce adulthood PCOS manifestations caused by prenatal excess androgen.

Keywords:Androgens; Exposure Time; Fetus; Polycystic Ovary Syndrome; Rats

\section{Background}

Polycystic ovary syndrome (PCOS) is one of the most common reproductive disorders in women with prevalences of $8-12 \%$ in reproductive ages (1). The most important reproductive and metabolic characteristics of PCOS are oligomenorrhea, amenorrhea, oligoovulation, anovulation, infertility, luteinizing hormone (LH) hypersecretion, hyperandrogenism and hyperinsulinemia $(2,3)$. Due to its peripubertal onset and familial clustering, PCOS is known as an autosomal dominant genetic disease (4). On the other hand, there is a lack of reliable association between genotype and phenotype of this syndrome (5), indicating that beside genetic factors, environmental factors may also contribute to development and appearance of PCOS.

Previous studies have shown that prenatal exposure of female fetuses to androgen hormones can be considered an important factor in the development of PCOS (6); such exposure also induces changes in female repro-

\section{Implication for Health Policy/Practice/Research/Medical Education:}

The time of prenatal exposure to androgens may have a significant role in development of PCOS, which is associated with reduction of morphological disorders of the reproductive system. Therefore avoiding exposure to androgen excess during critical periods of fetal development may prevent or reduce adulthood PCOS manifestations caused by prenatal excess androgen.

Copyright ( ) 2014, Research Institute For Endocrine Sciences and Iran Endocrine Society; Published by Kowsar Corp. This is an open-access article distributed under the terms of the Creative Commons Attribution License, which permits unrestricted use, distribution, and reproduction in any medium, provided the original work is properly cited. 
Ramezani Tehrani F et al.

ductive phenotype in adulthood (7). Other studies conducted in humans and animals suggest that exposure of females to androgen during early life (prenatal, perinatal or early postnatal life) may lead to development of PCOS phenotype in adulthood $(2,8,9)$. Both congenital adrenal hyperplasia caused by 21-hydroxylase deficiency and congenital excess androgen secretion from the adrenal can lead to an increased incidence of PCOS (2). These studies have shown that androgen excess during the fetal period may be associated with PCOS. Recently, experiments in animals revealed that the etiology of PCOS may be related to excess androgen, which could interfere with the function of the hypothalamus-pituitary-gonad axis and contribute to reproductive dysfunction in adults (2). Several studies have introduced animal models of PCOS to assess the effects of prenatal exposure of animals to androgen excess; for example in mice, rats, sheep and monkeys, prenatal androgenized animals showed many symptoms of PCOS after puberty such as hyperandrogenemia, increased LH secretion, polycystic ovary, oligoovulation and some others $(2,5$, $10,11)$. Rat or mouse models of PCOS may be preferred to other animal models, due to their stable genetic backgrounds, ease of handling and maintenance, shorter reproductive lifespan and generation times, feasibility of genetic manipulations and their short lifespan. It has been reported that the effect of androgen on the female reproductive system is highly influenced by the time of exposure $(2,5)$.

\section{Objectives}

We aimed to examine the effects of prenatal exposure of female rat fetuses to previous documented doses of testosterone on different embryonic days on the development of PCOS phenotype in adulthood.

\section{Materials and Methods}

\subsection{Animals}

Thirty-two female Wistar rats with body weights of 170-190 g (age 70-90 days) were obtained from the animal center of Research Institute for Endocrine Sciences (RIES) of Shahid Beheshti University of Medical Sciences (SBUMS) (Tehran, Iran). Male and female animals (one each) were housed in a polypropylene cage $(43 \mathrm{~cm} \times 30$ $\mathrm{cm} \times 15 \mathrm{~cm}$ ) overnight in an environmentally controlled room (temperature $22 \pm 3^{\circ} \mathrm{C}$, relative humidity $45-55 \%$ with 12-h light/dark cycles). Observation of the vaginal plug was considered as the first day of pregnancy. Pregnant rats were randomly divided into two experimental groups and two vehicle groups (controls), (8 in each group). Animals were handled according to the principles of laboratory animals care approved by the local ethics committee of Research Institute for Endocrine Sciences (RIES) of Shahid Beheshti University of Medical
Sciences (SBUMS) (Tehran, Iran); (320 EC 90.09.07).

\subsection{Hormone Injection}

The time and dosage of testosterone injection were set according to previous studies $(2,12)$.

In experimental group 1, pregnant rats were injected daily with $3 \mathrm{mg}$ of free testosterone subcutaneously (T1500, Sigma, Germany) dissolved in a $500 \mu \mathrm{L}$ cocktail containing sesame oil (S3547, Sigma, Germany) and benzyl benzoate (B6630, Sigma, Germany) with a ratio of 4:1, on gestational days 16-19. Each rat in control group 1 was injected with $500 \mu \mathrm{L}$ of the cocktail. In experimental group 2, pregnant rats were injected with $20 \mathrm{mg}$ of free testosterone subcutaneously dissolved in $1 \mathrm{ml}$ solvent on day 20 of the gestational period, while its control group received $1 \mathrm{ml}$ of the solvent.

The female offspring of these mothers were examined for the development and function of the reproductive system at the age of 90-100 days (in adulthood) and for anogenital distance (AGD); (which is the distance (mm) between the cranial edge of the anus and the base of clitoris) at days 6, 30 and 60 .

\subsection{Determination of Body Weight, Morphologi- cal Parameters and Organs Weight}

Body weight of female offspring was measured at birth and days 15, 30, 45 and 60 after birth. AGD was measured $(\mathrm{mm})$ by Vernier calipers at the age of 6, 30, 60 days. In adulthood all morphological parameters including AGD, clitoris length, number of nipples, vaginal length and kidney to ovary (k-o) distance were measured; prenatal androgenized female offspring were also examined for existence of male organs including ventral prostate, seminal vesicle and bulbourethral glands. Body weight and the weights of brain, adrenal glands and ovaries were determined. Absolute weight of organs was measured by digital scale (Sartorius, Germany) with $0.1 \mathrm{mg}$ accuracy.

\subsection{Blood Sampling}

Female offspring were anesthetized by intraperitoneal (i.p) injection of pentobarbital sodium (P3761, 5mg, Sigma, USA) dissolved in normal saline $0.9 \%$ (60 mg/ $\mathrm{kg}$ body weight) in adulthood. Blood was collected from the abdominal aorta in micro centrifuge tubes, centrifuged at $10000 \mathrm{rpm}, 4^{\circ} \mathrm{C}$, for $5 \mathrm{~min}$. Sera were stored at $-80^{\circ} \mathrm{C}$ for subsequent measurement of hormone levels (Testosterone (T), Luteinizing Hormone (LH), FollicleStimulating-Hormone (FSH), Estrogen (E2), Progesterone (P), anti-Mullerian hormone (AMH) and Sex-Hormone-Binding-Globulin (SHBG)).

\subsection{Hormone Measurement}

Rat specific ELISA kits, (Rat T ELISA kit, Cat No: CSB- 
E05100r, LH Cat No: CSB-E06869r, FSH Cat No: CSBE12654r, E2 Cat No: CSB-05110r, P Cat No: CSB-E07282r, AMH Cat No: CSB-E11162r, SHBG Cat No CSB-E08234r, CUSABIO BIOTECH CO., LTD, Japan) were used to measure hormone levels. Intra-assay coefficients of variations for all hormones were less than $10 \%$.

\subsection{Histological Evaluation}

Following anesthetization, adult rats were killed by heart incision; ovaries were removed, placed in $4 \%$ paraformaldehyde in phosphate-buffered saline (PBS) at room temperature for 3 days, processed by standard protocols and embedded in paraffin. Sections of the ovary with 4 - $\mu$ m thickness were prepared, deparaffinized by xylene, hydrated by an ethanol series (100\%, 90\%, $80 \%, 70 \%$ and $50 \%$ ) and distilled water, and stained using Hematoxylin Harris and Eosin Y (H\&E). Sections were mounted and observed by light microscope (100 x magnifications). The number of preantral, antral, preovulatory follicles as well as the number of corpora luteaper ovary were determined by counting 5 representative sections per ovary at least $20 \mu \mathrm{m}$ apart (2). Follicles and corpora lutea were counted in the ovarian sections with similar size (approximately) between the all groups. To avoid duplicate counting, follicles and corpora lutea were counted by two persons and only follicles with an oocyte visible were counted.

\subsection{Statistical Analysis}

Data are expressed as mean \pm SEM. Independent-sample student t test was used to compare the results between the experimental groups and their controls. SPSS 15.0 PC package (SPSS Inc., Chicago, IL) was used for data analysis. P values $<0.05$ were considered statistically significant.

\section{Results}

\subsection{The Number of Female and Male Offspring in Each Group}

In control group 1, total number of offspring was 70 (39 females +31 males), in experimental group 1, was 88 ( 47 females +41 males), in control group 2, was 70 (34 female +36 male) and in experimental group 2, was 72 (44 females +28 males).

\subsection{Body weight, Morphological Parameters and Organs Weight}

Changes in the body weights are presented in Table 1. There were no significant differences between experimental groups 1 and 2 compared to their controls at any time, except at birth in experimental group 1 compared to its controls.

Morphological parameters and organs weight in the experimental and control groups are also presented in Table 1. According to our results, AGD in the offspring of both experimental groups was significantly increased compared to their controls at all measurement times ( $P$ $<0.001)$. Clitoris length was significantly increased in the offspring of both experimental groups in comparison to controls (in experimental group $1 \mathrm{P}<0.001$ and in experimental group $2 \mathrm{P}<0.05)$. Nipples were not formed in the offspring of the experimental group 1 , whereas in the offspring of the experimental group 2 the number of nipples was unchanged compared to controls. Vaginal length was significantly decreased in the offspring of experimental group 1 compared to controls $(\mathrm{P}<0.001)$, whereas in the offspring of experimental group 2, no significant difference was observed compared to controls $(P>0.05)$. Male organs including ventral prostate, seminal vesicle and bulbourethral glands were not observed in the female offspring in either of the experimental groups in adulthood.

\subsection{Hormone Levels}

Figures 1 and 2 illustrate the hormonal profiles of female offspring of experimental and control groups in adulthood. In experimental group 1, hormonal profiles did not differ compared to its controls, whereas in group 2 , levels of testosterone $(\mathrm{P} \leq 0.05)$ and $\mathrm{LH}(\mathrm{P}<0.01)$ were significantly increased, and estrogen and anti-Mullerian hormone levels were significantly decreased $(\mathrm{P}<0.05$ and $\mathrm{P}<0.001$, respectively) compared to its controls.

\subsection{Histological Changes of the Ovary}

A significant increase was observed in the number of preantral and antral follicles in the ovaries of offspring of experimental group 1 in comparison to controls $(\mathrm{P}<$ 0.001). However, there were no significant differences in the number of preantral and antral follicles of offspring of experimental group 2 in comparison to controls (Table 2 and Figure 3). The number of preantral and antral follicles, preovulatory follicles and corpora lutea per ovary in the female offspring of experimental and control groups are reported in Table 2.

\section{Discussion}

The present study showed that exposure of female fetuses to exogenous testosterone during embryonic days 16-19, produced developmental and morphological disorders in reproductive system and androgen-sensitive tissues in female offspring, however its hormonal profiles remained intact. On the other hand, exposure to exogenous testosterone on embryonic day 20 , had little effect on the morphology but induced more obvious endocrine disturbances, similar to those observed in PCOS subjects. The novelty of this research was the time of androgen exposure, exposure to exogenous androgen for female fetuses was concurrent with the androgen surge in male fetuses of rats, (an androgen surge is present in 
male fetuses of rats beginning on embryonic day 16 and lasting until embryonic day 21) (13). This period of female fetus development may be a critical period to androgen exposure. In the present study we aimed to observe polycystic ovary syndrome (PCOS) features in female rats in adulthood by providing prenatal exposure to documented dosages of testosterone at the critical period of fetal development.

Alterations in AGD, nipple, reproductive tract and external genitalia found in our study are in agreement with the findings of previous studies (2, 13-15). Due to the presence of androgen receptors, exposure to androgens before the final development of reproductive tract and androgen-sensitive tissues leads to the male-like morphology in external genital system; some studies reported male-like tissues in their androgenized female animals (13-15) which was not observed in this study; this inconsistency may be explained by differences in the time and androgen dosage duration of exposure and also type of androgen or animal strain.

Table 1. Body Weight of Female Offspring of Experimental and Control Groups at Birthday and on Days 15, 30, 45, 60 after birth and in Adulthood and Morphological Parameters and Weight of Organs in Adulthood a,b,c

\begin{tabular}{|c|c|c|c|c|c|c|}
\hline \multirow[t]{2}{*}{ Parameters } & \multicolumn{6}{|c|}{ Groups } \\
\hline & $\begin{array}{l}\text { Control } 1 \\
(\mathbf{n}=\mathbf{8})\end{array}$ & $\begin{array}{l}\text { Experimental } 1 \\
(\mathbf{n}=\mathbf{9})\end{array}$ & PValue & $\begin{array}{l}\text { Control } 2 \\
(\mathbf{n}=11)\end{array}$ & $\begin{array}{l}\text { Experimental } 2 \\
(\mathbf{n}=\mathbf{9})\end{array}$ & P Value \\
\hline At birth, $g$ & $5.59 \pm 0.15$ & $6.08 \pm 0.15^{d}$ & 0.04 & $5.74 \pm 0.11$ & $5.78 \pm 0.1$ & 0.83 \\
\hline On day $15, \mathrm{~g}$ & $19.75 \pm 1.63$ & $21.13 \pm 0.62$ & 0.42 & $21.72 \pm 0.44$ & $24.11 \pm 1.87$ & 0.24 \\
\hline On day $30, g$ & $46.12 \pm 4.04$ & $48.11 \pm 1.63$ & 0.64 & $57.27 \pm 3.65$ & $54.77 \pm 3.68$ & 0.64 \\
\hline On day $45, g$ & $87.12 \pm 5.8$ & $93 \pm 2.9$ & 0.36 & $87 \pm 4.37$ & $80 \pm 2.58$ & 0.18 \\
\hline On day $60, \mathrm{~g}$ & $117.87 \pm 5.3$ & $126.55 \pm 3.39$ & 0.17 & $125.9 \pm 5.35$ & $135 \pm 4.87$ & 0.23 \\
\hline In adulthood, $\mathrm{g}$ & $156.25 \pm 5.74$ & $171.33 \pm 5.01$ & 0.06 & $162.45 \pm 5.69$ & $178.44 \pm 9.44$ & 0.14 \\
\hline \multicolumn{7}{|l|}{ Anogenital distance, $\mathrm{mm}$} \\
\hline Day 6 & $2.87 \pm 0.12$ & $4.44 \pm 0.17^{\mathrm{e}}$ & 0 & $2.63 \pm 0.15$ & $4.0 \pm 0.28 \mathrm{e}$ & 0 \\
\hline Day 630 & $7.5 \pm 0.18$ & $13.66 \pm 0.47^{\mathrm{e}}$ & 0 & $8.63 \pm 0.27$ & $12.88 \pm 0.77^{\mathrm{e}}$ & 0 \\
\hline Day 660 & $11.12 \pm 0.35$ & $19.77 \pm 0.27^{\mathrm{e}}$ & 0 & $10.81 \pm 0.26$ & $16.0 \pm 0.66^{\mathrm{e}}$ & 0 \\
\hline AGD in adulthood, mm & $11.12 \pm 0.35$ & $20.11 \pm 0.45^{\mathrm{e}}$ & 0 & $11.0 \pm 0.38$ & $16.22 \pm 0.57^{\mathrm{e}}$ & 0 \\
\hline Clitoris length, mm & $5.25 \pm 0.16$ & $8.22 \pm 0.52 \mathrm{e}^{\mathrm{e}}$ & 0 & $4.90 \pm 0.36$ & $6.33 \pm 0.57^{d}$ & 0.04 \\
\hline Nipple count & $12.0 \pm 0$ & $0^{e}$ & 0 & $12.0 \pm 0$ & $12.0 \pm 0$ & 0 \\
\hline Vaginal length, mm & $13.12 \pm 0.54$ & $2.77 \pm 0.27^{\mathrm{e}}$ & 0 & $13.72 \pm 0.76$ & $13.66 \pm 0.23$ & 0.19 \\
\hline Kidney to ovary distance, $\mathrm{mm}$ & $3.62 \pm 0.46$ & $5.11 \pm 1.18$ & 0.26 & $5.63 \pm 0.57$ & $4.66 \pm 0.66$ & 0.28 \\
\hline Brain weight, $\mathrm{g}$ (absolute) & $1.57 \pm 0.03$ & $1.65 \pm 0.01$ & 0.06 & $1.63 \pm 0.03$ & $1.65 \pm 0.04$ & 0.78 \\
\hline Brain weight (Relative) & $\begin{array}{l}0.0102 \pm \\
0.00038\end{array}$ & $0.0097 \pm 0.00027$ & 0.12 & $\begin{array}{l}0.0102 \pm \\
0.00033\end{array}$ & $0.0094 \pm 0.00041$ & 0.14 \\
\hline Paired adrenal weight, $\mathbf{g}$ (absolute) & $0.04 \pm 0$ & $0.05 \pm 0^{\mathrm{d}}$ & 0.02 & $0.03 \pm 0$ & $0.09 \pm 0.05$ & 0.27 \\
\hline Paired adrenal weight, $g$ (Relative) & $\begin{array}{l}0.0003 \pm \\
0.00002\end{array}$ & $\begin{array}{l}0.0003 \pm \\
0.00002\end{array}$ & 0.20 & $\begin{array}{l}0.0002 \pm \\
0.00002\end{array}$ & $0.0005 \pm 0.00023$ & 0.18 \\
\hline Paired ovary weight, $\mathrm{g}$ (absolute) & $0.10 \pm 0$ & $0.20 \pm 0.06$ & 0.16 & $0.11 \pm 0$ & $0.12 \pm 0.01$ & 0.25 \\
\hline Paired ovary weight, $g$ (Relative) & $\begin{array}{l}0.0006 \pm \\
0.00004\end{array}$ & $\begin{array}{l}0.0012 \pm \\
0.00040\end{array}$ & 0.15 & $\begin{array}{l}0.0007 \pm \\
0.00003\end{array}$ & $0.0007 \pm 0.00004$ & 0.31 \\
\hline
\end{tabular}

a Values are expressed as mean \pm SEM, independent-sample student $t$ test.

$\mathrm{b}$ Relative weight is organ weight/body weight.

${ }^{\mathrm{C}}$ Control 1, female offspring of control group 1; Experimental 1, female offspring of experimental group 1; Control 2, female offspring of control group

2; Experimental (2), female offspring of experimental group 2. Adulthood is 90-100 days of age.

$\mathrm{d} P<0.05$.

e $\mathrm{P}<0.001$ 
Figure 1. The Hormonal Profiles of Study Groups in Adulthood (90-100 Days of Age)
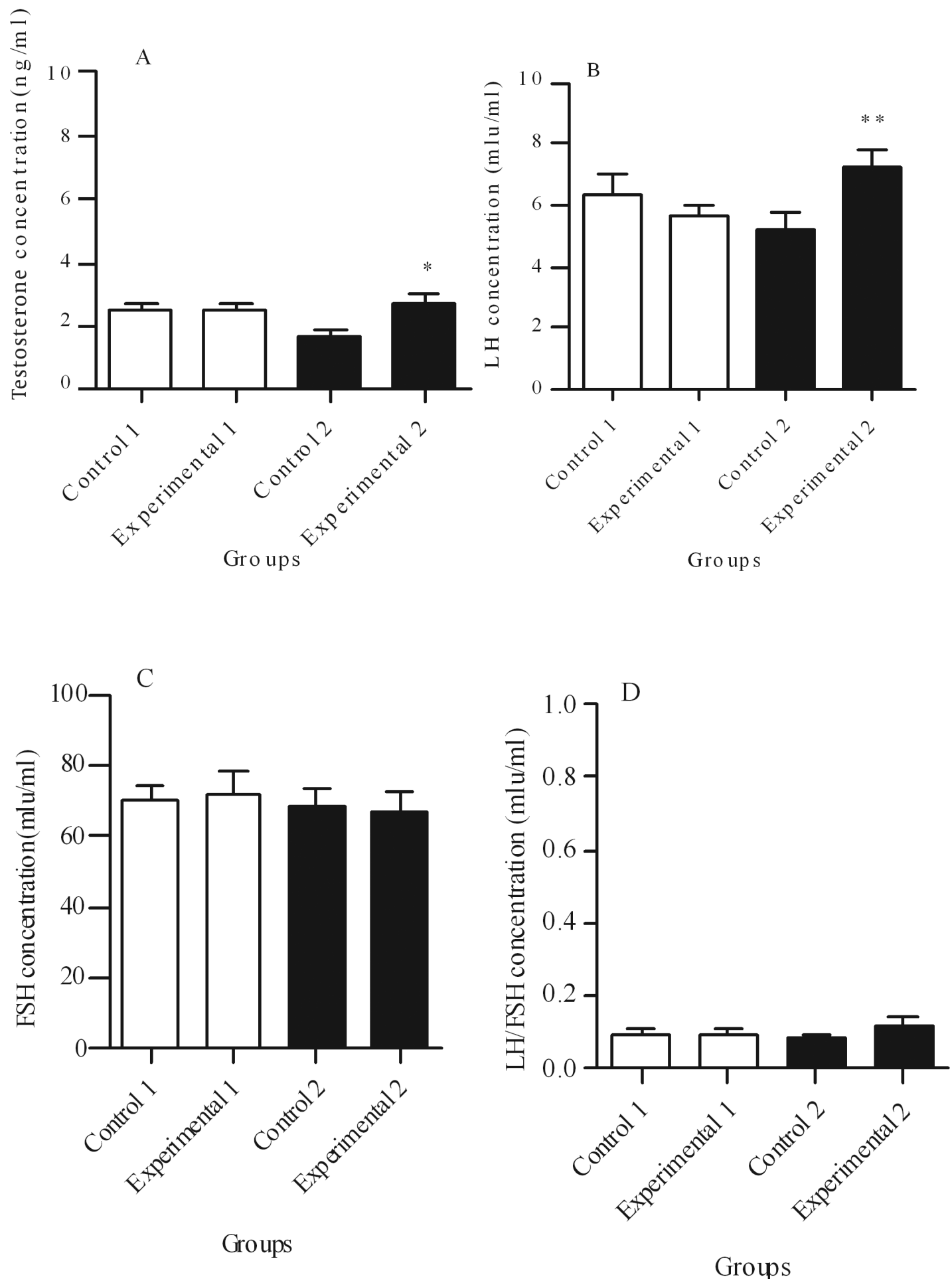

A: Comparison of testosterone concentration, B: Comparison of luteinizing hormone (LH) concentration, C: Comparison of follicle-stimulating-hormone (FSH) concentration, D: Comparison of the ratio of LH/FSH ratio between experimental groups and theirs controls. Values are expressed as mean \pm SEM, independent-sample student $t$ test was used. ${ }^{*} \mathrm{P}<0.05$ and ${ }^{* *} \mathrm{P}<0.01$. 
Figure 2. The Hormonal Profiles of Study Groups in Adulthood (90-100 Days of Age)

A

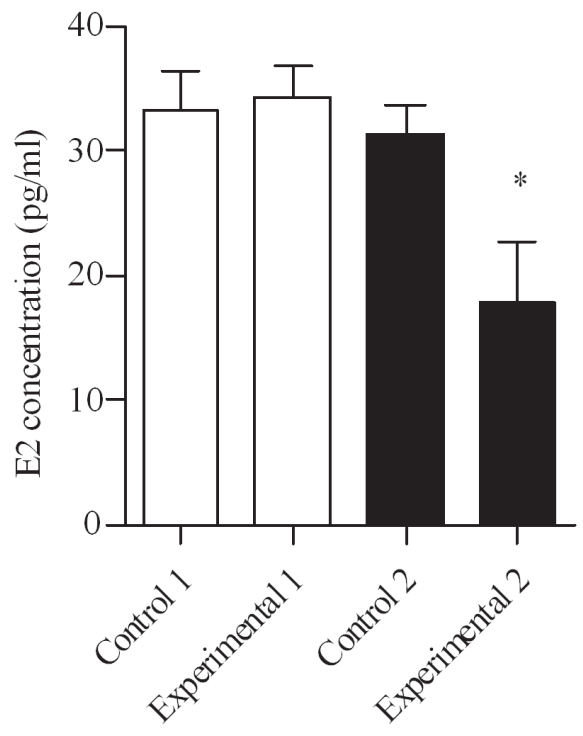

Groups
B

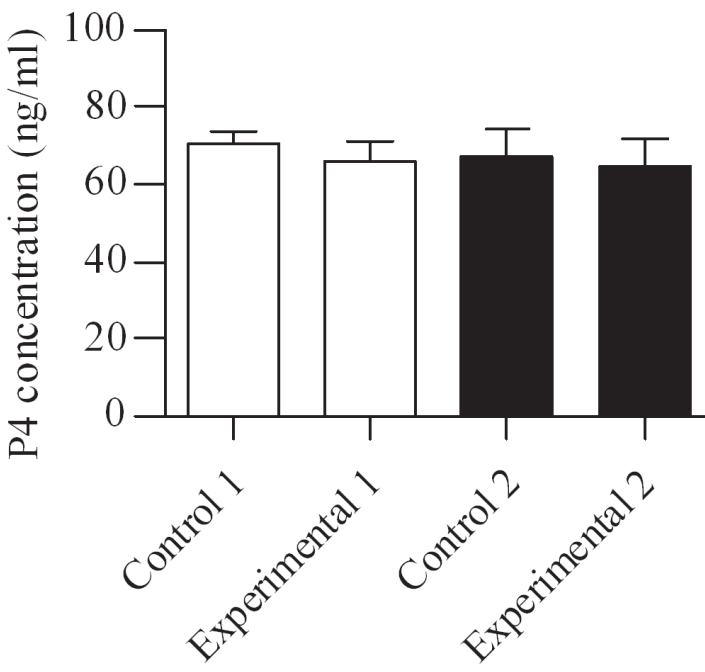

Groups
C

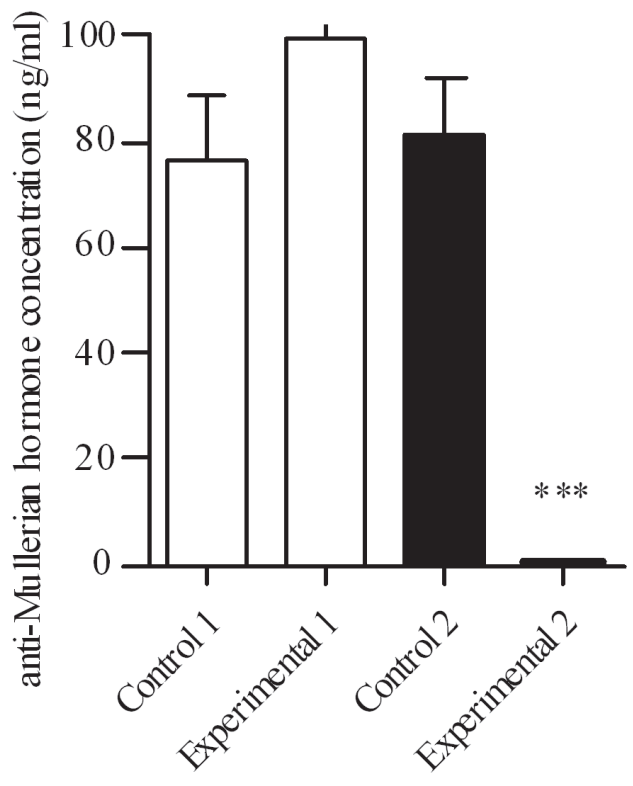

Groups
$\mathrm{D}$

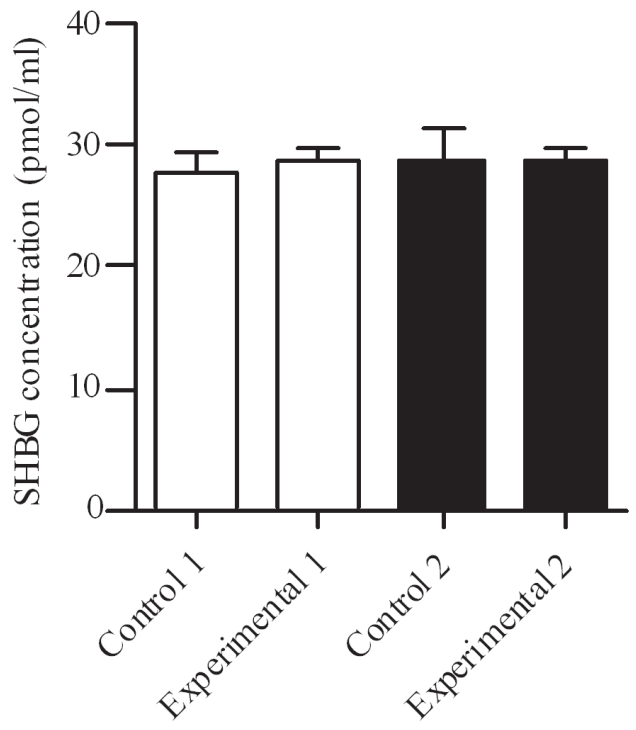

Groups

A: Comparison of estrogen concentration, B: Comparison of progesterone concentration, C: Comparison of anti-Mullerian hormone concentration, D: Comparison of sex-hormone-binding-globulin concentration between the experimental groups and controls. Values are expressed as mean \pm SEM, independent-sample student $t$ test was used. ${ }^{*} \mathrm{P}<0.05$ and ${ }^{* * *} \mathrm{P}<0.001$. 
Ramezani Tehrani F et al.

Table 2. The Number of Preantral Follicles, Antral Follicles, Preovulatory Follicles and Corpora Lutea per Ovary in Female Offspring of Experimental and Control Groups in Adulthood ${ }^{\mathrm{a}, \mathrm{b}, \mathrm{c}}$

\begin{tabular}{|c|c|c|c|c|c|c|}
\hline \multirow[t]{2}{*}{ Parameters } & \multicolumn{6}{|c|}{ Groups } \\
\hline & Control $1(n=5)$ & Experimental $1(n=5)$ & PValue & Control $2(n=5)$ & Experimental $2(n=6)$ & P Value \\
\hline $\begin{array}{l}\text { Number of preantral fol- } \\
\text { licles }\end{array}$ & $4.68 \pm 0.73$ & $8.60 \pm 0.91^{d}$ & 0.01 & $3.44 \pm 0.99$ & $7.40 \pm 1.37$ & 0.05 \\
\hline Number of antral follicles & $5.2 \pm 0.53$ & $14.40 \pm 2.0^{\mathrm{e}}$ & 0.002 & $10 \pm 2.60$ & $15.60 \pm 2.14$ & 0.14 \\
\hline $\begin{array}{l}\text { Number of preovulatory } \\
\text { follicles }\end{array}$ & $0.60 \pm 0.35$ & $0.16 \pm 0.09$ & 0.27 & $0.72 \pm 0.22$ & $0.53 \pm 0.19$ & 0.53 \\
\hline Number of corpora lutea & $9.28 \pm 1.77$ & $10.60 \pm 1.87$ & 0.62 & $10.76 \pm 0.99$ & $8.96 \pm 1.31$ & 0.32 \\
\hline
\end{tabular}
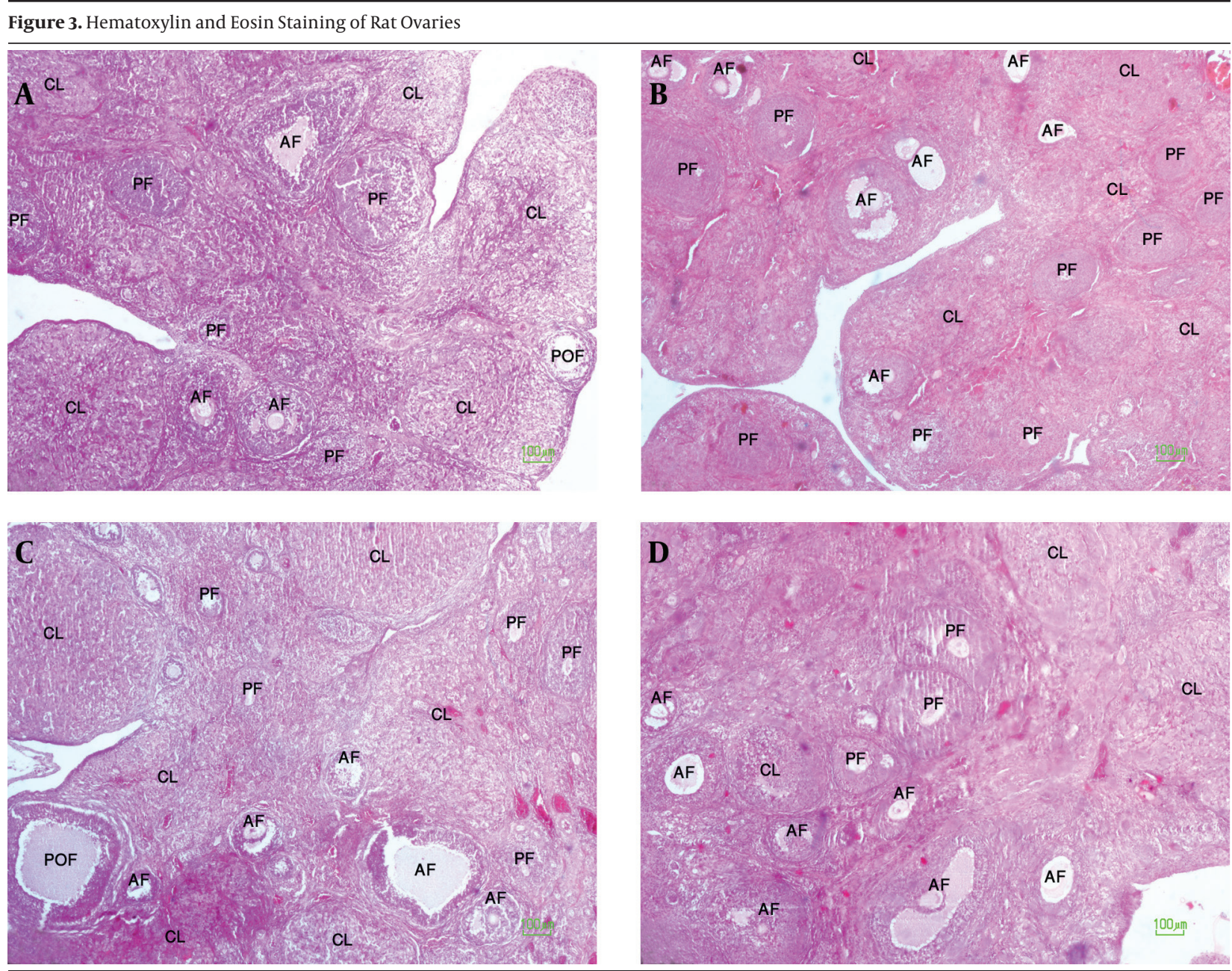

A: ovary tissue in female offspring of control group 1, B: ovary tissue in female offspring of experimental group 1, C: ovary tissue in female offspring of control group 2, D: ovary tissue in female offspring of experimental group 2. PF: Preantral follicle, AF: Antral follicle, POF: Preovulatory follicle, CL: corpus luteum (100 x magnifications).

In the current study, high serum LH concentration in adulthood was observed in female offspring of the experimental group 2, similar to those previously reported in monkey, sheep and mice models $(10,16,17)$ Previous studies reported that high frequency of GnRH pulsation in the hypothalamus leads to increased LH secretion from 
the pituitary gland, but a low frequency of GnRH pulsation leads to FSH secretion (10). Increased LH secretion in our study may be explained through two different mechanisms; first, accelerated GnRH pulse generator activity in the hypothalamus because of prenatal androgen effect; however it remained unclear how prenatal androgen receptor activation may program hyperactivity of GnRH pulse generator in adulthood. In female sheep exposed to androgen during prenatal life, synaptic contacts to GnRH neurons were reduced to lower levels observed in males (18), suggesting that the effects of androgens on GnRH pulsation may be mediated by alterations in synaptic connectivity; another study proposed that androgen receptor activation may create specific alterations in the drive from gamma-aminobutyric acid-releasing neurons to GnRH neurons (10). For the second mechanism, increase in LH may be due to reduction of negative feedback of sex steroids on the LH secretion. As in female monkeys exposed to androgen during early or late gestational period $(5,19,20)$ and in women with polycystic ovary syndrome $(21,22)$ diminished sex steroids negative feedback, leads to increased pulsatile LH secretion in human and animal, however these possible mechanisms

were not investigated in our study.

In our study an increase in the serum testosterone concentration was observed in female offspring of experimental group 2; this is an indicator of ovarian response to increased LH secretion which acts on theca cells causing elevated testosterone secretion. This finding is supported by an earlier study, where prenatally androgenized rats demonstrated high levels of LH after puberty, which was associated with elevation of testosterone level (2). However, in another study performed on prenatally androgenized mice, level of testosterone did not increase significantly at the age of 5 months despite LH elevation (23). Differences in these results may be explained by differences in the type of animals and their age at the time of examination, considering different results of hormonal profiles in prenatally androgenized animals and also differences in testosterone level at different ages according to previous studies $(23,24)$.

Serum FSH concentration in the offspring of experimental group 2 showed no difference compared to controls. A previous study on prenatal androgenized female rats also reported no alterations in the FSH level after puberty (2).

In the present study, a significant decrease was seen in the serum estrogen concentration of offspring of experimental group 2 compared to controls. This reduction may be explained by a decrease in the aromatase enzyme activity. Reduced aromatase activity inhibits the conversion of testosterone to estrogen, leading to low estrogen, but increased levels of testosterone, which may lead to PCOS (25). This hypothesis remains to be examined.

In our study, serum progesterone concentration did not show significant difference in the offspring of experimental group 2 in comparison with its controls, despite a non-significant decreasing trend in the number of corpus luteum. This may be due to the effect of increased LH levels on the corpus luteum, thereby preventing the reduction expected in progesterone levels.

Our findings showed a non-significant decreasing trend in the number of corpora lutea in offspring of experimental group 2, which may represent a decrease in ovulation; following lack of GnRH and LH surges due to prenatal excess of androgen. In female rodents, the preovulation GnRH surge depends on the ability of ovarian E2 to couple a daily neural signal (26-28), a process which appears to be mediated by steroid ability to induce progesterone receptor (Pgr) expression in the anteroventral periventricular (AVPv) nucleus $(27,28)$. Previous studies have suggested that lack of Pgr expression (29), reduces expression of Pgr in the $\operatorname{AVP}(27,30)$ or the Pgr antagonist (31-35) blocks E2- induced GnRH and LH surges. Studies have shown that prenatal exposure to excess androgen decreases E2-induced Pgr expression in the preoptic area (POA) (2); it has also been shown that prenatal androgen receptors activation leads to permanent refractoriness of the POA to Pgr-inducing actions of E2. Foecking et al. stated that activation of prenatal androgen receptors in female rats can prevent gonadotropin surge release in adulthood (36), as was previously observed in sheep (37$40)$ and monkeys (41).

Serum anti-Mullerian hormone concentration was significantly reduced in female offspring of experimental group 2, compared to controls. Findings of a studyperformed by Veiga-Lopez et al. on sheep, showed a reduction in expression of anti-Mullerian hormone in the preantral follicles and an increase in its expression in the antral follicles due to prenatal androgen excess (42).

Lack of changes in the hormone levels of female offspring in the experimental group 1 was in agreement with the results of Foecking et al (36). However, Wu et al. (2) investigated female rats exposed to exogenous androgen during embryonic days 16-19 and observed hormonal changes after puberty (2). Similar to their findings, we observed changes in the number of follicles in female offspring of experimental group 1; this finding may be due to reduced sensitivity of follicles to FSH, which needs to be further investigated. Differences in the time, duration, level of prenatal exposure to androgen, type of androgen and the strain and age of animals at the time of study could explain different results based on different hormonal profiles in prenatally androgenized animals at previous studies $(23,24)$.

The main strength of the present study was the time of androgen which was concurrent with production of an androgen surge in male fetuses of rats, (an androgen surge in male fetuses of rats beginning on embryonic day 16 and lasting until embryonic day 21) (13). This period of female fetus development may be a critical period for androgen exposure. In the present study we aimed to observe polycystic ovary syndrome (PCOS) features in female rats in adulthood by providing prenatal exposure 
to documented dosages of testosterone at the critical period of fetal development. We had some limitations; it is not clear that our observation was due to the differences of exposure time to androgen or the dosage of androgen. However, it has been reported that the effect of androgen on the female reproductive system is highly influenced by the time of exposure $(2,5)$. As the regards development of genitalia and nervous system of rats begins during fetal life and continues after birth (at birth, the genitalia and nervous system of rats are in the medium-term of differentiation and development), it seems that these systems are more sensitive to androgen in late fetal life. Therefore we think that the observed differences may be mainly influenced by the time of androgen exposure rather than its dosage. However, this needs more investigation.The time of exposure to androgens may have a significant role in the development of certain PCOS characteristics associated with reduction of morphological disorders of the reproductive system. Therefore, avoiding exposure to androgen excess during critical periods of fetal development may prevent or reduce adulthood PCOS manifestations.

\section{Acknowledgements}

We thank Abdollah Amini for helping in histology, Mehdi Hedayati for their lab assistance and Ms. Niloofar Shiva for critical editing of English grammar and syntax of the manuscript.

\section{Authors' contribution}

Fahimeh Ramezani Tehrani; contributed substantially to conception and design, analysis and interpretation of data, drafting of the manuscript and revised and approved the final version for publication. Mahsa Noroozzadeh; performed the data collection and laboratory tests, contributed substantially to analysis and interpretation of data and drafting of the manuscript. Saleh Zahediasl; contributed substantially to design, analysis, interpretation of data, drafting of the manuscript and revised and approved the final version for publication. Abbas Piryaei; contributed substantially to laboratory tests and histological assistance. Somayeh Hashemi; drafting of the manuscript. Fereidoun Azizi; contributed substantially to interpretation of data and drafting of the manuscript.

\section{Financial Disclosure}

The Authors declared no financial and material supports in this project.

\section{Funding/Support}

This work was supported by the project (No.320) of Research Institute for Endocrine Sciences, Shahid Beheshti University of Medical Sciences, Tehran, Iran.

\section{References}

1. Franks S. Assessment and management of anovulatory infertility in polycystic ovary syndrome. Endocrinol Metab Clin North Am. 2003;32(3):639-51.

2. Wu XY, Li ZL, Wu CY, Liu YM, Lin H, Wang SH, et al. Endocrine traits of polycystic ovary syndrome in prenatally androgenized female Sprague-Dawley rats. Endocr J. 2010;57(3):201-9.

3. Amalfi S, Velez LM, Heber MF, Vighi S, Ferreira SR, Orozco AV, et al. Prenatal hyperandrogenization induces metabolic and endocrine alterations which depend on the levels of testosterone exposure. PLoS One. 2012;7(5).

4. Legro RS, Spielman R, Urbanek M, Driscoll D, Strauss JF, 3rd, Dunaif $A$. Phenotype and genotype in polycystic ovary syndrome. Recent Prog Horm Res. 1998;53:217-56.

5. Abbott DH, Barnett DK, Bruns CM, Dumesic DA. Androgen excess fetal programming of female reproduction: a developmental aetiology for polycystic ovary syndrome? Hum Reprod Update. 2005;11(4):357-74.

6. Li Z, Huang H. Epigenetic abnormality: a possible mechanism underlying the fetal origin of polycystic ovary syndrome. Med Hypotheses. 2008;70(3):638-42.

7. Ryan BC, Vandenbergh JG. Intrauterine position effects. Neurosci Biobehav Rev. 2002;26(6):665-78.

8. Ibanez L, Dimartino-Nardi J, Potau N, Saenger P. Premature adrenarche--normal variant or forerunner of adult disease? Endocr Rev. 2000;21(6):671-96.

9. McCartney CR, Blank SK, Prendergast KA, Chhabra S, Eagleson CA, Helm KD, et al. Obesity and sex steroid changes across puberty: evidence for marked hyperandrogenemia in pre- and early pubertal obese girls. J Clin Endocrinol Metab. 2007;92(2):430-6.

10. Sullivan SD, Moenter SM. Prenatal androgens alter GABAergic drive to gonadotropin-releasing hormone neurons: implications for a common fertility disorder. Proc Natl Acad Sci U S A. 2004;101(18):7129-34.

11. Recabarren SE, Padmanabhan V, Codner E, Lobos A, Duran C, Vidal $\mathrm{M}$, et al. Postnatal developmental consequences of altered insulin sensitivity in female sheep treated prenatally with testosterone. Am J Physiol Endocrinol Metab. 2005;289(5):E801-6.

12. Swanson HE, Werfftenbosch JJ. The "Early-Androgen" Syndrome; Differences in Response to Pre-Natal and Post-Natal Administration of Various Doses of Testosterone Propionate in Female and Male Rats. Acta Endocrinol (Copenh). 1964;47:37-50.

13. Hotchkiss AK, Lambright CS, Ostby IS, Parks-Saldutti L, Vandenbergh JG, Gray LE, Jr.. Prenatal testosterone exposure permanently masculinizes anogenital distance, nipple development, and reproductive tract morphology in female Sprague-Dawley rats. Toxicol Sci. 2007;96(2):335-45.

14. Wolf CJ, Hotchkiss A, Ostby JS, LeBlanc GA, Gray LE, Jr.. Effects of prenatal testosterone propionate on the sexual development of male and female rats: a dose-response study. Toxicol Sci. 2002;65(1):71-86.

15. Dean A, Smith LB, Macpherson S, Sharpe RM. The effect of dihydrotestosterone exposure during or prior to the masculinization programming window on reproductive development in male and female rats. Int JAndrol. 2012;35(3):330-9.

16. Matwijiw I, Faiman C. Control of gonadotropin secretion in the ovine fetus. IV. Male-specific entrainment of the hypothalamic control of luteinizing hormone secretion by testosterone in the female ovine fetus. Endocrinology. 1991;129(3):1447-51.

17. Dumesic DA, Abbott DH, Eisner JR, Goy RW. Prenatal exposure of female rhesus monkeys to testosterone propionate increases serum luteinizing hormone levels in adulthood. Fertil Steril. 1997;67(1):155-63.

18. Kim SJ, Foster DL, Wood RI. Prenatal testosterone masculinizes synaptic input to gonadotropin-releasing hormone neurons in sheep. Biol Reprod. 1999;61(3):599-605.

19. Steiner RA, Clifton DK, Spies HG, Resko JA. Sexual differentiation and feedback control of luteinizing hormone secretion in the rhesus monkey. Biol Reprod.1976;15(2):206-12.

20. Dumesic DA, Schramm RD, Abbott DH. Early origins of polycystic 
ovary syndrome. Reprod Fertil Dev. 2005;17(3):349-60.

21. Daniels TL, Berga SL. Resistance of gonadotropin releasing hormone drive to sex steroid-induced suppression in hyperandrogenic anovulation. J Clin Endocrinol Metab. 1997;82(12):4179-83.

22. Eagleson CA, Gingrich MB, Pastor CL, Arora TK, Burt CM, Evans WS, et al. Polycystic ovarian syndrome: evidence that flutamide restores sensitivity of the gonadotropin-releasing hormone pulse generator to inhibition by estradiol and progesterone. $J$ Clin Endocrinol Metab. 2000;85(11):4047-52.

23. Roland AV, Nunemaker CS, Keller SR, Moenter SM. Prenatal androgen exposure programs metabolic dysfunction in female mice. J Endocrinol. 2010;207(2):213-23.

24. Walters KA, Allan CM, Handelsman DJ. Rodent models for human polycystic ovary syndrome. Biol Reprod. 2012;86(5):149-12.

25. Manneras L, Cajander S, Holmang A, Seleskovic Z, Lystig T, Lonn $\mathrm{M}$, et al. A new rat model exhibiting both ovarian and metabolic characteristics of polycystic ovary syndrome. Endocrinology. 2007;148(8):3781-91.

26. Everett JW, Sawyer CH. A 24-hour periodicity in the "LH-release apparatus" of female rats, disclosed by barbiturate sedation. Endocrinology. 1950;47(3):198-218.

27. Levine JE. New concepts of the neuroendocrine regulation of gonadotropin surges in rats. Biol Reprod. 1997;56(2):293-302.

28. Chappell PE, Lee J, Levine JE. Stimulation of gonadotropin-releasing hormone surges by estrogen. II. Role of cyclic adenosine 3'5'-monophosphate. Endocrinology. 2000;141(4):1486-92.

29. Chappell PE, Schneider JS, Kim P, Xu M, Lydon JP, O'Malley BW, et al. Absence of gonadotropin surges and gonadotropin-releasing hormone self-priming in ovariectomized (OVX), estrogen (E2)-treated, progesterone receptor knockout (PRKO) mice. Endocrinology. 1999;140(8):3653-8.

30. Chappell PE, Levine JE. Stimulation of gonadotropin-releasing hormone surges by estrogen. I. Role of hypothalamic progesterone receptors. Endocrinology. 2000;141(4):1477-85.

31. Collins RL, Hodgen GD. Blockade of the spontaneous midcycle gonadotropin surge in monkeys by RU 486: a progesterone antagonist or agonist? J Clin Endocrinol Metab. 1986;63(6):1270-6.

32. Bauer-Dantoin AC, Tabesh B, Norgle JR, Levine JE. RU486 administration blocks neuropeptide $\mathrm{Y}$ potentiation of luteinizing hormone (LH)-releasing hormone-induced LH surges in proestrous rats. Endocrinology. 1993;133(6):2418-23.

33. Batista MC, Cartledge TP, Zellmer AW, Nieman LK, Loriaux DL,
Merriam GR. The antiprogestin RU486 delays the midcycle gonadotropin surge and ovulation in gonadotropin-releasing hormone-induced cycles. Fertil Steril. 1994;62(1):28-34.

34. Szabo M, Knox KL, Ringstrom SJ, Perlyn CA, Sutandi S, Schwartz NB. Mechanism of the inhibitory action of RU486 on the secondary follicle-stimulating hormone surge. Endocrinology. 1996;137(1):85-9.

35. Bellido C, Gonzalez D, Aguilar R, Sanchez-Criado JE. Antiprogestins RU486 and ZK299 suppress basal and LHRH-stimulated FSH and LH secretion at pituitary level in the rat in an oestrous cycle stage-dependent manner. J Endocrinol.1999;163(1):79-85.

36. Foecking EM, Szabo M, Schwartz NB, Levine JE. Neuroendocrine consequences of prenatal androgen exposure in the female rat: absence of luteinizing hormone surges, suppression of progesterone receptor gene expression, and acceleration of the gonadotropin-releasing hormone pulse generator. Biol Reprod. 2005;72(6):1475-83.

37. Herbosa CG, Dahl GE, Evans NP, Pelt J, Wood RI, Foster DL. Sexual differentiation of the surge mode of gonadotropin secretion: prenatal androgens abolish the gonadotropin-releasing hormone surge in the sheep. J Neuroendocrinol. 1996;8(8):627-33.

38. Masek KS, Wood RI, Foster DL. Prenatal dihydrotestosterone differentially masculinizes tonic and surge modes of luteinizing hormone secretion in sheep. Endocrinology. 1999;140(8):345966.

39. Robinson JE, Birch RA, Foster DL, Padmanabhan V. Prenatal exposure of the ovine fetus to androgens sexually differentiates the steroid feedback mechanisms that control gonadotropin releasing hormone secretion and disrupts ovarian cycles. Arch Sex Behav. 2002;31(1):35-41.

40. Sharma TP, Herkimer C, West C, Ye W, Birch R, Robinson JE, et al. Fetal programming: prenatal androgen disrupts positive feedback actions of estradiol but does not affect timing of puberty in female sheep. Biol Reprod. 2002;66(4):924-33.

41. Zeleznik AJ, Little-Ihrig L, Ramasawamy S. Administration of dihydrotestosterone to rhesus monkeys inhibits gonadotropinstimulated ovarian steroidogenesis. J Clin Endocrinol Metab. 2004;89(2):860-6.

42. Veiga-Lopez A, Ye W, Padmanabhan V. Developmental program ming: prenatal testosterone excess disrupts anti-Mullerian hormone expression in preantral and antral follicles. Fertil Steril. 2012;97(3):748-56. 